\title{
Implications and Challenges of Coal as a Source of Energy
}

\author{
*Odia O. Osadolor and Uwhubetine O. Best \\ Faculty of Engineering and Technology, Ambrose Alli University, Ekpoma, Nigeria.
}

\begin{abstract}
The high tempo of industrialization that was precipitated by industrial revolution changed the pattern of energy use. High temperatures are necessary when heat is to be converted into mechanical energy and these high temperatures are easily derived from high-energy concentrated sources. Thus apart from the depletion of wood as a source of energy, the quest for high energy concentrated sources led man to discover fossil fuels and their conversion principles. Coal, the most abundant fossil fuel has a distribution that is so wide that it is usually not necessary to import or export large amount of it. Incidentally most of the major industrialized nations have large coal deposits, thus further reducing the need for large-scale international trade in coal. Using old and new literatures, and interpolating and extrapolating some of the information, the amount of coal that has been used till date was estimated and its effects determined. It was also deduced that the world total consumption of coal from 1700 to 2011 which was estimated to be 175,186,562,325 tonnes also emitted an estimated amount of 642,935 million tonnes of $\mathrm{CO}_{2}$ into the atmosphere while world total coal reserves on the planet earth pre-industrial revolution was estimated to be 1,036,124,562,000 tonnes.
\end{abstract}

Keywords: Coal, Consumption, Reserves, Atmosphere, Emitted, $\mathrm{CO}_{2}$

\section{Introduction}

Before the industrial revolution, energy needs were modest, for heat, man relied on the sun or burn wood or straw when the sun fails while for transportation, the muscle of animals and the power of the wind in sails took man to every corner of the world. Similarly, animals were used to do works that could not be done with man's power while water and wind drove the simple machines that were later invented to grind the grains and pumped water. The high tempo of industrialization that was precipitated by the industrial revolution that started in Britain changed the pattern of energy use. High temperatures are necessary when heat is to be converted into mechanical energy and these high temperatures are easily derived from high-energy concentrated sources. Thus apart from the depletion of wood as a source of energy, the quest for high energy concentrated sources led man to discover fossil fuels and their conversion principles. Today, fossil fuel powers most of the conventional technologies in industries, transportation, agriculture and domestic life. Fossil fuels are combustible substances of organic origin capable of exothermic reaction in the presence of oxygen supplied directly or extracted from air (Crawford 1987; Gaver et al, 1986; Meadows and Meadows, 1992;).

Coal, the most abundant fossil fuel, is thought to be partially decayed remains of vegetation, which grew on wet lands such as swamps, bogs and marshes.This compacted vegetation in the absence of air and under the influence of high temperature and pressure will continue to undergo transformation. As the aging process progresses, the coal become harder, hydrogen and oxygen content decreases, and the carbon content increases(LeBel, 1982; Nef, 1977; Masters, et al 1997;).

The distribution of coal is so wide that it is usually not necessary to import or export large amount of coal. Incidentally most of the major industrial nations have large coal deposits, thus further reducing the need for large-scale international trade in coal. It is impossible to estimate accurately the amount of mineablecoal in the world. Coal is a good industrial and domestic fuel. There are technologies for its conversion into other types of fuel that can prime small units like cars but the cheap availabilityof petroleum resources is making these technologies competitively expensive at least for the now(Pearce and Turner, 1998; Ross and Williams, 1981).

Coal is composed primarily of carbon along with variable quantities of other elements, chiefly hydrogen, sulfur, oxygen, and nitrogen,(Blander, 2011). Throughout history, coal has been a useful resource. It is now primarily burnt for the production of electricity. Coal is the largest source of energy for the generation of electricity worldwide, as well as one of the largest worldwide anthropogenic (Scott,(2008)) sources of carbon dioxide released (Wikipedia). Coal is burnt to produce heat energy and is used to manufacture steel. Fuel companies also often convert coal into energy transportable fuel (gasoline and diesel) which is produce through the process of thermal or catalytic cracking. The resulting fuel also known as synthetic fuel could be liquid or gaseous fuel. The aim of this work is to investigate some of the effects of the use of coal on the environment.

\section{Methodology}

Usingold and new literatures, and interpolating and extrapolating some of the information, the amount of coal that has been used till date can be estimated and its effects determined. Coal mining can result in a 
number of adverse effects on the environment. Surface mining of coal completely eliminates existing vegetation, destroys the genetic soil profile, displaces or destroys wildlife habitat, degrades air quality, alters current land uses, and to some extent permanently changes the general topography of the area mined. During the burning of coal, carbon dioxide $\left(\mathrm{CO}_{2}\right)$ which is the main byproduct is released. The contribution of $\mathrm{CO}_{2}$ to global climate change is one of the fundamental problems of fossil fuel on the economy.

Carbon dioxide $\left(\mathrm{CO}_{2}\right)$ is a colour less and odour less gas formed by the combustion of carbon and the respiration of animals and is considered a greenhouse gas. There are both natural and human sources of carbon dioxide. The natural sources include decomposition, ocean release and respiration. Wright, Kemp, \& Williams (2011), defined carbon footprintas the sum of all emissions of $\mathrm{CO}_{2}$ (carbon dioxide), which were induced by humans' activities in a given time frame. Usually a carbon footprint is calculated for the time period of a year. Since the industrial revolution atmospheric concentration of carbon dioxide has been rising. Seventy-two percent $(72 \%)$ of the totally emitted greenhouse gas is $\mathrm{CO}_{2}$. It is a very important greenhouse gas since when released into the atmosphere it remains for 100 to 200 years leading to its increasing concentration in the atmosphere which in turn causes average temperature on the earth to rise.

\section{Results}

Coal proved reserve is generally taken to be those quantities which geological and engineering information indicates with reasonable certainty can be recovered in the future from deposit under existing economic and operating conditions. The rate of production and consumption combined with the proved reserves are as shown in table 1. To estimate total amount of coal that have been mined and used from the pre-industrial revolution era, that is, from the year 1700, tables 2 was generated by interpolation and extrapolation from table 1. And adding the total consumption of $175,186,562,325$ tonnes from 1700 to 2011 and its present proved reserves of $860,938,000,000$ tonnes it will give the estimated amount of the pre-industrial coal reserves. Consequently, the pre-industrial coal reserve is estimated at about 1,036,124,562,325 tonnes.

Table 1: World Coal Production, Consumption and Proved Reserves
\begin{tabular}{|l|l|l|l|}
\hline Year & $\begin{array}{l}\text { Total World } \\
\text { Production } \\
\text { Million Tonnes }\end{array}$ & $\begin{array}{l}\text { TOTAL World } \\
\text { Consumption } \\
\text { Millions Tonnes }\end{array}$ & $\begin{array}{l}\text { Total Proved Reserves } \\
\text { Proved } \\
\text { Million Tonnes }\end{array}$ \\
\hline 1991 & 4557.127 & 3525.523 & 981780 \\
\hline 1992 & 4519.215 & 3485.793 & 981499 \\
\hline 1993 & 4395.781 & 3496.961 & 980585 \\
\hline 1994 & 4484.125 & 3522.259 & 981239 \\
\hline 1995 & 4605.409 & 3616.11 & 982138 \\
\hline 1996 & 4680.157 & 3679.829 & 982692 \\
\hline 1997 & 4730.399 & 3705.555 & 983064 \\
\hline 1998 & 4651.902 & 3687.372 & 982482 \\
\hline 1999 & 4638.229 & 3710.803 & 982381 \\
\hline 2000 & 4701.418 & 3842.99 & 982849 \\
\hline 2001 & 4917.917 & 3857.369 & 984453 \\
\hline 2002 & 4960.761 & 3957.91 & 982545 \\
\hline 2003 & 5313.802 & 4273.09 & 966847 \\
\hline 2004 & 5723.105 & 4599.652 & 948646 \\
\hline 2005 & 6049.043 & 4831.313 & 934153 \\
\hline 2006 & 6356.513 & 5085.207 & 920478 \\
\hline 2007 & 6588.29 & 5292.964 & 910171 \\
\hline 2008 & 6822.116 & 5384.994 & 899773 \\
\hline 2009 & 6904.639 & 5421.432 & 896103 \\
\hline 2010 & 7254.589 & 5721.834 & 880541 \\
\hline 2011 & 7695.441 & 6033.433 & 860938 \\
\hline Sour & British Petrol & Statical Revies & $92012)$ \\
\hline
\end{tabular}

Source: British Petroleum Statistical Review (2012)

Table 3: Estimation of Coal Consumption

\begin{tabular}{|l|l|l|l|l|l|}
\hline Year & Tonnes & Year & Tonnes & Year & Tonnes \\
\hline 1700 & $3,318,300$ & 1960 & 1942382168 & 1990 & 3575284000 \\
\hline 1710 & $4,258,485$ & 1965 & 2311730000 & 1991 & 3525523000 \\
\hline 1720 & $5,198,670$ & 1966 & 2338761000 & 1992 & 3485793000 \\
\hline 1730 & $6,138,855$ & 1967 & 2303223000 & 1993 & 3496961000 \\
\hline 1740 & $7,079,040$ & 1968 & 2337395000 & 1994 & 3522259000 \\
\hline 1750 & $8,019,225$ & 1969 & 2390199000 & 1995 & 3616110000 \\
\hline 1760 & $8,959,410$ & 1970 & 2428873000 & 1996 & 3679829000 \\
\hline 1770 & $9,899,595$ & 1971 & 2413553000 & 1997 & 3705555000 \\
\hline 1780 & $10,839,780$ & 1972 & 2447640000 & 1998 & 3687372000 \\
\hline 1790 & $11,779,965$ & 1973 & 2516662000 & 1999 & 3710803000 \\
\hline 1800 & $12,720,150$ & 1974 & 2513994000 & 2000 & 3842990000 \\
\hline
\end{tabular}




\begin{tabular}{|c|c|c|c|c|c|}
\hline 1810 & $19,541,100$ & 1975 & 2570501000 & 2001 & 3857369000 \\
\hline 1820 & $31,482,837$ & 1976 & 2672804000 & 2002 & 3957910000 \\
\hline 1830 & $33,183,000$ & 1977 & 2761281000 & 2003 & 4273090000 \\
\hline 1840 & $61,388,550$ & 1978 & 2802797000 & 2004 & 4599652000 \\
\hline 1850 & $89,594,100$ & 1979 & 2913740000 & 2005 & 4831313000 \\
\hline 1860 & $164,022,378$ & 1980 & 2922535000 & 2006 & 5085207000 \\
\hline 1870 & $235,709,910$ & 1981 & 2944952000 & 2007 & 5292964000 \\
\hline 1880 & $365,344,830$ & 1982 & 2988434000 & 2008 & 5384994000 \\
\hline 1890 & $556,700,130$ & 1983 & 3068917000 & 2009 & 5421432000 \\
\hline 1900 & $835,547,940$ & 1984 & 3209126000 & 2010 & 5721834000 \\
\hline 1910 & $912,832,074$ & 1985 & 3341101000 & 2011 & $6,033,433,000$ \\
\hline 1920 & $1,060,205,385$ & 1986 & 3391646000 & & \\
\hline 1930 & $1,162,448,961$ & 1987 & 3518143000 & Total & $175,186,562,325$ \\
\hline 1940 & $1,386,499,837$ & 1988 & 3619768000 & & \\
\hline 1950 & $1,557,816,650$ & 1989 & 3648199000 & & \\
\hline
\end{tabular}

From elementary chemistry it is stated that matter cannot be created non destroyed. The combustion of coal as earlier stated will yield carbon dioxide principally among other products. Tony(2008) deduced that one tonne of coal combust to produce 3.67 tonnes of carbon dioxide. This implies that the 175,186,562,325 tonnes of coal estimated to have been burnt in this work would have produce 642,935 million tonnes of carbon dioxide. Therefore, the estimated amount of $\mathrm{CO}_{2}$ emitted into the atmosphere by coal through its consumption from 1700 to 2011 is about 642,935 million tonnes.

\section{Discussion}

The result has shown that $175,186,562,325$ tonnes of coal has been consumed and that consumption is on the increase.The rate of depletion of the proved reserves are also increasing indicating that coal will exhausted in not too distant future. It has also been deduced that the world total consumption of coal from 1700 to 2011 which has been estimated to be 175,186,562,325 tonnes has emitted an estimated amount of about642,935 million tonnes of $\mathrm{CO}_{2}$ into the atmosphere while world total coal reserves on the planet earth pre-industrial are estimated to be $1,036,124,562,000$ tonnes.

\section{Conclusion}

$175,186,562,325$ tonnes of coal has been removed from the earth between the year 1700 and 2011 which in turn has emitted an estimated amount of 642,935 million tonnes of $\mathrm{CO}_{2}$ into the atmosphere thus destabilizing the earth's system resulting in global warming as one of the consequences. Also the rate at which the consumption is increasing is alarming and if not checked by sourcing alternate energy resources, the earth is definitely heading for a catastrophe.

\section{Reference}

[1]. Crawford M.; 1987, Back to the Energy Crisis, Science, (pp 626-7)

[2]. Gaver J., Kaufmann R., Skole D. and Vorosmarty C.; 1986, Beyond oil, Ballinger, Cambridge, MA.

[3]. LeBelP.G; 1982, Energy Economics and Technology; Johns Hopkins Press, Baltimore.

[4]. NefT.U.; 1977, An Early Energy Crisis And Its Consequences, Scientific American, October, pp 141-51.

[5]. Masters C.D., Root R.M. and Turner R.M.; October 1997, World Resources Statistics Geared for Electronic Access; Oil and Gas Journal

[6]. Meadows D.H and Meadows D.L.; 1992,Beyond the Limits, Chelsea Green Publishers, Burlinton

[7]. Pearce D.W. and Turner R.k; Economics of Natural Resources and the Environment, John Hopkins University Press Baltimore

[8]. Ross M.H. and Williams R.H.; 1981, Our Energy-Regaining Control, McGraw-Hill, New York

[9]. Balogun, I.O and Dada, S.S (2005). Diversification of Energy Sources for Sustainable Economic development in Nigeria: The Role of Coal. Multi disciplinary Journal of Research Development of National Association for Research Development, 2(7).

[10]. Blander,M (1999). Calculation of the Influence of Additives on Coal Combustion Deposits. http/www.anl.ov/pcs/aisfuel/preprint\%20archives/files/voluones/vol34-2pdf

[11]. British Petroleum (2012).Statistical Review of World Energy 2012.

[12]. www.bp.com/.../bp.../energy.../statistical...

[13]. Edward, B (1905, March, 13). World Coal Production.Boston Evening Transcript.www.news.google?nd=19050313\&id

[14]. Smith.C (1988). The Science of Energy-A Cultural History of Energy in Victorian Britain. Chicago, The University of Chicago Press.

[15]. Oscar, V; Erik, M; Hugh, P; Rona, D; Douglas, S and Serge, W (2009).Carbon payments as a Safeguard for Threatened tropical mammals.A Journal of the Society for Conservation Biology.Vol 2: 89-90

[16]. Tailor,T, Tailor,E and Krings, M (2009). Paleaobotancy: The Biology and Evolution of Fossil plant

[17]. TonyfromOz (2008).why Does One Tonne of Coal Make 2.86 Tonnes of Carbon dioxde. www.papundits.wordpress.com/2008/12/14. Wikipedia. Coal. http/www.enwikipedia.org.wiki/coal.

[18]. Wright, L; Kemp, S \& Williams, I (2011): 'Carbon Foot Printing': Towards a Universally Accepted Definition. Carbon Management, 2 (1), 61-72 